\title{
Transformaciones de la poesía chilena entre 1973 y $1988^{*}$
}

\author{
Transformations in the Chilean poetry between \\ 1973 and 1988 \\ Naín Nómez \\ Universidad de Santiago de Chile, Departamento de Idiomas, Santiago, Chile. \\ e-mail: nnomez@lauca.usach.cl
}

\begin{abstract}
Este es un recuento crítico de carácter global del desarrollo de la poesía chilena durante el período dictatorial delimitado entre 1973 y 1988, que muestra la articulación entre los procesos histórico-sociales del país y las transformaciones que ocurren en los discursos literarios. En cada uno de los tres momentos que conforman el período se establecen relaciones entre los discursos poéticos que se extienden más allá de las fronteras, con los procesos del campo literario-cultural y las representaciones histórico-sociales, cuyos avances y retrocesos repercuten a la vez que son impactados por la producción del campo en sus restricciones y ampliaciones. En las conclusiones se entregan algunas reflexiones provisorias y generales sobre el sentido de algunas representaciones poéticas del período en relación al gobierno dictatorial y el proceso de la modernidad.
\end{abstract}

Palabras clave: poesía chilena, historia cultural, dictadura, postvanguardia, postmodernidad.

This paper gives a global vision of the Chilean poetry during the dictatorial period 1973-1978, and shows the relationship between the historical/social processes in the country and the transformations that occurred in literary discourse. Some relationships between the poetic discourse which goes beyond frontiers and the literary/cultural and the historical/social representations are established in each of the three stages the dictatorial period has been divided. These processes have forward and backward repercussions, but at the same time they are impacted by the literary field in its restriction and extension.

In the conclusion, some tentative and general reflections are given about the meaning of some poetic representations concerning the dictatorial government and the process of modernism.

Key words: Chilean poetry, cultural history, dictatorship, post-vanguard, postmodernism.

\section{INTRODUCCIÓN}

La mayor dificultad para el estudio de la poesía durante el período dictatorial, así como la recepción crítica que lo sustenta, disciplina y/o fisura, tiene que ver con los hechos histórico-políticos de fondo. Como ha señalado Tomás Moulián (1997), existe una etapa terrorista que se inicia en 1973 y culmina en 1980 cuando se aprueba la Constitución y se legaliza la dictadura. Pero dentro de esta primera etapa hay un período oscuro que dura hasta 1977 cuando se inicia el transformismo o trasvestismo del proceso de cambio dictatorial que culmina en 1988. El proyecto se articuló a través del monopolio jurídico, el monopolio del saber y el despliegue del terror. En este contexto, la intervención militar provocó una escisión, una fragmentación cultural que, por un lado, inhibió las fuerzas productivas de la literatura del interior y, por otro, produjo un vuelco fundamental en la escritura de los poetas que salieron al exilio o que vivían fuera del país desde antes. El golpe militar representó un corte que modificó formas, temas, relaciones territoriales, maneras de difundir las producciones, incluyendo las limitaciones de su recepción crítica. La crónica, el testimonio, las memorias, los discursos y otras escrituras más directas o emocionales reemplazaron la estética de la mediación simbólica. En el interior del país predominó la publicación artesanal y secreta, con las excepciones de los poetas proclives al régimen. Los poetas exiliados se centraron en la inmediatez de la realidad histórica o exaltaron con nostalgia el mundo que quedó atrás, convirtiendo las emisiones suecas, mexicanas, norteamericanas, canadienses o francesas casi siempre en testimonios panfletarios en verso. 
Este podemos focalizarlo entre 1973 y 1977, presenta fuertes articulaciones entre la historia y las representaciones discursivas del imaginario, no sólo desde el punto de vista de una simbólica de la realidad, sino también por el repliegue generalizado de toda forma de comunicación que no fuera la censuradora del oficialismo. Existe también una relación directa entre esta fase terrorista de la dictadura con la incapacidad de los escritores para comunicar el imaginario que se vive debido a la pérdida de toda comunicación y recepción crítica. No existen derechos formales ni saber teórico, excepto el dogmatismo del sistema, la totalidad del poder político en manos de las Fuerzas Armadas y el Orden del Terror que se concentra especialmente en el recurso de los detenidos-desaparecidos.

Desde el punto de vista de la poesía no hay grandes transformaciones estéticas en los poetas que surgen en el período, si exceptuamos aquellos con una obra recorrida, los que continuaron escribiendo con un énfasis mayor en la realidad política del momento. Es el caso de los poetas de los cincuenta (como, por ejemplo, Armando Uribe, Efraín Barquero, Enrique Lihn, Jorge Teillier, Rolando Cárdenas) y de los sesenta (Waldo Rojas, Omar Lara, Gonzalo Millán, Jorge Etcheverry, Manuel Silva Acevedo, Cecilia Vicuña, entre otros). En el interior, entre tanto, el panfleto es la forma más socorrida de la escritura poética, en este caso, al servicio de la resistencia contestataria. El repliegue se centra en versos que pasan de mano en mano o se publican en forma artesanal y casi en forma anónima para denunciar y criticar el estado de cosas. El primer poema conocido de este tipo es "Somos cinco mil", un poema escrito por Víctor Jara poco antes de ser asesinado en el estadio Chile. Muchas de estas producciones serán reproducidas más tarde en revistas como Literatura chilena en el exilio, que se inicia en California en 1977 bajo la dirección de Fernando Alegría y David Valjalo o en Araucaria, dirigida en Madrid por Volodia Teitelboim desde 1978. Las líneas primordiales que se desarrollan dentro de Chile son las de denuncia política y crítica social, primordialmente clandestinas y utilizadas como guía de acción; la literatura oficial, poco estructurada y concentrada en algunos novelistas, poetas y dramaturgos alabados por el régimen, muchos de los cuales posteriormente se pasaron al lado crítico, y la poesía autocensurada que al buscar nuevas formas de expresión para "decir no diciendo", provocó su propia transformación estética.

En esta última dirección y con alguna timidez afloran algunos textos de clausura y ruptura casi desconocidos por el repliegue de la distribución y el borramiento de la recepción. Las escasas manifestaciones artísticas de esos años, que hacen hablar a las autoridades de apagón cultural, se reactivan hacia 1975. La ofensiva de la cultura oficial se refugia en una Secretaría de la Juventud y en los mecanismos tradicionales de las Casas Culturales y las Asociaciones controladas. Se utiliza el despliegue publicitario para levantar un Festival de la Canción Internacional en Viña del Mar o una Fiesta Primaveral en que se invierten millones de pesos. La cultura popular en forma larvada sobrevive en las peñas folclóricas permitidas, los grupos musicales marginales, la artesanía, la poesía callejera y algunos espectáculos masivos. Uno de los rasgos más significativos de la reacomodación de la cultura a la situación represiva es el uso del chiste como material de recuperación literaria y política. Los críticos han llamado la atención sobre algunos poetas (Carrasco 1989; Campos 1990, 1980; Macías 1990; Harris 1998; Cánovas 1986; Rodríguez 1995; Jamal 1988, entre otros), que empiezan a escribir bajo otras concepciones estéticas en esos años, aunque probablemente venían haciéndolo desde antes del Golpe. Una publicación importante al interior del país es la revista Manuscritos, editada por el Departamento de Estudios Humanísticos de la Universidad de Chile en 1975. En ella se muestran los primeros pasos de una ruptura cultural con el sistema que se instala en el repliegue, nuevas formas cuestionantes del sistema literario anterior, pero también del presente político. Su Comité de Redacción estaba conformado, entre otros, por Enrique Lihn, Alejandro Jodorowsky, Luis Oyarzún y Nicanor Parra y en ella aparecían trabajos experimentales del propio Parra, de Ronald Kay, de Jorge Guzmán y de Raúl Zurita (el fragmento "Areas verdes" publicado después en Purgatorio). Otros poetas que de tanto en tanto publican en revistas de circulación restringida en esos años son Juan Cameron y Juan Luis Martínez, este último autor de La nueva novela, que aparecerá en 1977, pero que fue escrita entre 1968 y 1975.

Por lo tanto, teniendo en cuenta las restricciones vigentes y la falta de producción y circulación de los productos culturales, es hacia el final de la primera etapa que podemos visualizar las primeras publicaciones que dan cuenta de ciertos cambios estéticos. Estos se equilibran entre la necesidad de establecer una simbólica que traspase la censura vigente y la necesidad de desarrollar una renovación que devuelva el poder de los significantes a la poesía, en contraposición al necesario estallido panfletario de los primeros años de dictadura. La característica de este primer período había sido la protección del sistema dictatorial a través del terror y el derecho refrendado por el Acta de Constitución de la Junta, que excluía otros modos de pensamiento como antisaberes (Moulián, op. cit.). La legalización de la represión mediante los estados de excepción se validó con las Actas Constitucionales que actuaron como un cepo 
sobre la ciudadanía. En este contexto, la poesía de los primeros años es fundamentalmente intimista y muestra su desgarro con el mundo exterior, como en el caso de Lucia Penna con su libro Mi propio océano publicado en 1974 o la obra Voz reunida (1975) del conocido poeta Julio Barrenechea, donde los fantasmas dan cuenta anticipada de su propia muerte. Entre 1976 y 1977 se inicia un proceso de paulatina ruptura con la ofensiva cultural oficialista que preconiza el apaciguamiento e inicia su operación transformista. Esta operación tiene sus antecedentes en el revuelo causado por el asesinato de Letelier, la desaparición de la dirección clandestina del Partido Comunista y los impactos que causaron en la opinión mundial. La división al interior de la cúpula militar provoca la necesidad de legitimar la dictadura mediante una transición hacia una "democracia restringida". Se plantearon tres etapas: la de recuperación que iba de 1973 a 1980; la de transición hasta fines de 1985, y una de normalidad que se iniciaría allí. En agosto de 1977 se disuelve la DINA, el general Manuel Contreras es llamado a retiro y se crea la CNI, que tenía menos atribuciones. Se inician las primeras desaveniencias entre Gustavo Leigh y Pinochet y entre avances y retrocesos, la Junta Militar inicia el Anteproyecto de la Nueva Constitución.

En este panorama de aperturas y cepos, la Sociedad de Escritores de Chile toma una decidida actitud crítica y organiza sus primeros encuentros nacionales que muy pronto intentarán involucrar a los escritores que viven en el exterior. De 1976 es la antología Astrolabio y otros libros de Jaime Quezada y El jardín de las palabras de Jaime Gómez Rogers (Jonás). Publican también en ese momento Jorge Jobet, Los granos y las hojas; Inés Moreno, Umbral de la luz; Alfonso Calderón, Isla de los bienaventurados y Daisy Bennet, Vértigo: todas producciones que despliegan claves personales de diverso cuño frente a la situación represiva. Enrique Lihn, que había publicado en 1975 Por fuerza mayor, un texto trabajado antes en "Los sonetos del energúmeno", con París, situación irregular (1977), muestra una metáfora del Chile de ese momento y colabora en la creación de un campo experimental, que reelabora sus claves para hablar en forma velada de la censura y la violencia. Lo mismo hace Nicanor Parra con la publicación de Sermones y prédicas del Cristo de Elqui. Manuel Silva Acevedo, por su parte, escribe una de las obras más emblemáticas del período: Lobos y ovejas. Grínor Rojo señalaba en 1983 que es un hito esencial de la literatura chilena en las últimas décadas y un símil descarnado de la situación del país, a pesar de sus claves aptas para pasar y repasar la censura. Lo interesante de este poemario es que fue escrito varios años antes del Golpe Militar y el propósito de su autor fue purificarse de una situación amorosa negativa. Poemas anónimos de otros poetas con un fuerte contenido político (como Oscar Hahn y Ana María Vergara) circulan también en el anonimato. Una antología que aparece bajo el sello de Tamarugal editada por Daisy Bennet y Ariel Fernández y titulada Poetas chilenos de hoy presenta el trabajo de taller de un grupo de 13 poetas, de relativo interés, pero que es un síntoma de aperturas transitorias bajo nuevas clausuras. Durante ese mismo año aparece una antología de poesía de la Unión de Escritores Jóvenes con el nombre de Poesía para el camino, con un prólogo de Roque Esteban Scarpa y un Manifiesto de Fidel Sepúlveda Llanos. El antologador y presidente de la agrupación, Ricardo Wilson, indica en la introducción el cambio que se está produciendo: "Ha quedado atrás el café con sus conversaciones de cuatro sillas. Encerrado el murmullo de las vidrieras. ¡Perdón! La joven poesía sale a la calle. Va del árbol hacia el bosque, va de sur a norte, enraizándose con los hombres, arremangándose la camisa en su paso cotidiano" (p. 9). Destacan los trabajos de Armando Rubio, Erick Pohlhammer, Antonio Gil, Bárbara Délano y el propio Ricardo Wilson.

En ese momento se ha producido una cierta renovación de las organizaciones sociales y populares, una reagrupación de los sectores más progresistas de la iglesia y una recuperación de los sectores sindicales y estudiantiles, así como acercamientos y contactos esporádicos, pero importantes, entre la cultura de dentro y de fuera. Sin embargo, hay que considerar que en general entre 1973 y 1983 existe una desmovilización pública, tanto por la desintegración de los partidos políticos como por el hecho de que las fuerzas antidictatoriales pensaban que la dictadura caería por su propio peso. En el exilio, a los primeros textos contestatarios de poetas como Efraín Barquero en Francia con El poema negro de Chile (1974), Omar Lara en Rumania con Serpiente (1974) y Oh Buenas maneras (ganador del Premio Casa de las Américas en 1975) y Crónica del Reyno de Chile de 1976; de Hernán Miranda con La Moneda y otros poemas de 1976, el cual también obtendría el Premio Casa de las Américas de Cuba; de Manuel Segundo Garrido con El desterrado Antiscio de 1976 en México u Oscar Hahn radicado en Estados Unidos, quien publica en Buenos Aires Arte de morir en 1977, se sucede una enorme cantidad de publicaciones en Francia, Canadá, Alemania, México, Venezuela y muchos otros países. Es en función de los cambios que empiezan a marcarse dentro del país y los nuevos vasos comunicantes que se establecen entre los poetas chilenos de otros lugares, incluyendo Chile, que las estéticas se ensanchan, dialogan y se multiplican para dar paso a una nueva etapa marcada por una mayor rigurosidad, que no descarta lo político pero lo subsume en nuevas formas discursivas. 


\section{EL SEGUNDO MOMENTO}

Alrededor de 1977 se inicia un segundo período, con la producción de diversas estéticas que tanto dentro como fuera del país buscan establecer una clausura con las tradiciones anteriores en algunos casos, mientras que por otros, las nuevas experiencias geográficas, históricas, culturales o sociales ayudan a replantearse la producción anterior de un poeta o de un grupo. De este modo, se comienza a conformar un vasto tejido escritural que tiene diversos escenarios, de los cuales tentativamente podemos focalizar los siguientes.

La Sociedad de Escritores de Chile inicia una serie de concursos anuales que tiene por centro el homenaje a los grandes poetas nacionales: Mistral, Neruda, Huidobro. En este sentido, se intenta revertir el oscurantismo literario del país, relevando a autores ya canonizados, para de este modo combatir la posible censura. Por otro lado, la Unión de Escritores Jóvenes intenta realizar eventos literarios y editar algunos libros como es el caso de Signos de Jonás, así como la antología Uno más uno de 1979, en donde, entre otros, publican Teresa Calderón, Marcelo Mellado y Natasha Valdés. En estas publicaciones aparecen ya muchos signos de cambio estético incrustado en una protesta larvada y sumergida, pero fuertemente antisistémica. Se percibe un cierto repliegue en algunos poetas, como el caso de Jorge Teillier que publica en 1978 Para un pueblo fantasma (una especie de mirada retrospectiva de su propia producción); esto va acompañado de nuevas fórmulas estéticas, destacando textos como Hombrecito verde (1979) de David Turkeltaub, Variaciones ornamentales (1979) de Ronald Kay, Perro de circo (1979) de Juan Cameron y especialmente la publicación de La nueva novela (1977) de Juan Luis Martínez y Purgatorio (1979) de Raúl Zurita. En estos dos últimos se percibe en forma fehaciente la renovación que se está desarrollando en términos de una experimentación ligada a toda la tradición occidental, por un lado, y una profunda imbricación en la contingencia del país, por otro. Muchos críticos han incursionado en la importancia de estos textos en la apertura estética que se produce en esos momentos en Chile, incluyendo el surgimiento del multifacético grupo CADA (creado en 1979) y la diversidad de líneas poéticas y pictóricas que afloran en los ochenta. El intento de Martínez busca destruir los supuestos textuales y extratextuales de la escritura poética y horadarse a sí mismo como discurso integral. Su obra expresa un punto extremo de búsqueda entre las nuevas representaciones poéticas, al intentar la despersonalización total del texto. Purgatorio, de Zurita, supera la noción de texto, para incorporar el espacio del cuerpo y la realidad como soportes de la escritura, explorando también las posibilidades traumáticas del dolor para metaforizar las agresiones sufridas por el cuerpo social. Para ello utiliza elementos de la escatología judeocristiana, especialmente los símbolos del mesianismo y la revelación. La figura del poeta-autor-sujeto del poema adopta la forma edificante de un redentor "postmoderno" que por medio de la revelación del lenguaje busca redimir al pueblo oprimido al mismo tiempo que la palabra poética adquiere un poder exorcizante frente a la legitimación bastarda de la palabra estatal, a su violencia simbólica y epistemológica.

La obra de Zurita tiene una evidente filiación con otros poetas posteriores, como el propio Cameron, Gonzalo Muñoz (Exit, 1981), Diego Maquieira (La Tirana, 1983), Carlos Cociña (Aguas servidas, 1981), Rodrigo Lira (Proyecto de obras completas, terminada en 1982 pero publicada en 1984) y Eugenia Brito (Vía pública en 1984), con los cuales asimila la búsqueda de nuevos significantes y espacios de la escritura, la elaboración de elementos gráficos, la despersonalización del sujeto, la autorreflexibilidad y la interacción arte-vida que alguna vez obsesionara a las vanguardias, elementos que a juicio de Carrasco (art. cit.) se expanden hacia la interdisciplinariedad y la mutación del género poético, en un ente híbrido que incorpora un sinnúmero de formas culturales. El propio Zurita, intentará, en 1983, justificar en un polémico ensayo "Literatura, lenguaje y sociedad 19731983” su postura estética desde una perspectiva casi generacional. Dirá que a su juicio la tradición poética chilena contemporánea se puede resumir en cuatro líneas fundamentales: la escritura nerudiana, parriana, lárica y epigramática. Enseguida integra toda la poesía del exilio dentro de estas cuatro líneas y expresa que en Chile existen dos grandes núcleos escriturales: la que define como una línea tradicional y la escritura nueva dentro de la cual se manifiesta su propia obra. Esta poesía nueva, que incluye unos 10 o 12 poetas, se caracterizaría por una propuesta y una visión de mundo diferente, con sus propias proposiciones poemáticas, sin ribetes neorrománticos, sin identificación con el receptor ni la expresión de un yo caído en el mundo o desgarrado por la existencia. Estos textos, además, presentarían un mundo separado de la realidad inmediata y su base de comprensión sería su propia descripción interna. La capacidad elusiva de estos textos, a su juicio, elude la censura del sistema represor de la dictadura, que no encuentra una significación política inmediata en los textos. También 
ayuda a recuperar un lenguaje gastado por la manipulación de los partes oficiales y los medios de comunicación del sistema. Se constituiría como un lenguaje autónomo con sus propias reglas, axiomas y principios gestados al interior del poema y como parte de una significación aterrizada en el lenguaje como totalidad. Además de Juan Luis Martínez, Zurita incluye entre estos poetas a Antonio Gil, Paulo Jolly, Diego Maquieira y también a varios de los citados anteriormente.

Habría que señalar que, siendo esta una de las interpretaciones más interesantes sobre la poesía chilena del período, no deja de ser subjetiva y autoglorificadora. Desde Humberto Díaz-Casanueva, pasando por Gonzalo Rojas, Efraín Barquero, Armando Uribe, David Rosenmann Taub, sin dejar de incluir a Oscar Hahn, Waldo Rojas, Silva Acevedo, Jorge Etcheverry, Gonzalo Millán o Tomás Harris, pasando por la vasta producción de poetas mujeres de los años ochenta y noventa, sería difícil meter en el lecho de Procusto enunciado por Zurita más arriba a todos estos autores. Si bien hay una continuidad con la tradición en un buen número de poetas del período, que es evidente, ni Zurita ni Juan Luis Martínez con toda su innovación, experimentación, transmutación y resignificación discursiva escapan a la articulación que tienen con la poesía anterior, por muy oblicua, mediada y distanciada que sea.

Paralelamente, otros jóvenes menos experimentales y más ligados a la contingencia intentan publicar algunas revistas, como es el caso de Eduardo Yentzen y La Bicicleta, que desde 1978 incluye poemas en sus páginas y se publica intermitentemente hasta 1987, convirtiéndose en sus últimos años en una especie de cancionero. Tuvo corresponsales en varios países, entre los cuales aparecían varias figuras relevantes, como es el caso de Ariel Dorfman y Mario Vargas Llosa. La Bicicleta fue una revista contestataria y popular que se asumió desde la partida en contraposición a los grupos literarios anteriormente descritos. Muchos de los poetas "insurgentes" publicaron sus primeros textos en la revista. Su objetivo consistió en facilitar "espacios sociales desde la vida cotidiana", publicitar actividades como recitales y encuentros alternativos y valorar lo local y lo regional. Como órgano de expresión creó espacios de encuentro y de producción artística incorporando la reflexión colectiva sobre lo popular, la identidad cultural, la función del artista dentro de un sistema autoritario y el arte como espacio autónomo de lo político. La revista fue un actor importante en el Chile de la dictadura y aunque finalmente se convirtió en un cancionero popular, nunca dejó de tener el sello de la crítica y la actitud contestataria. En 1979 aparece la revista Pazquín, de corta vida y que se presenta como órgano de expresión de la Unión de Escritores Jóvenes. También en ella se mostró una amplia gama de formas y expresiones literarias y se replanteó el problema de las posibilidades rupturistas de los escritores jóvenes y su papel en la democratización de la sociedad. El Taller "Ariel” edita una publicación ese mismo año hecha a mimeógrafo, incluyendo los ganadores de su propio certamen poético anual. Por su parte, Leonora Vicuña organizó el Cuaderno de poesía que reunió trabajos de unos 30 poetas jóvenes. Paralelamente apareció la editorial Ganímedes dirigida por el poeta David Turkeltaub, que se lanzó con la publicación de Sermones y prédicas del Cristo de Elqui de Nicanor Parra y posteriormente de libros de Enrique Lihn y Jorge Edwards, hasta realizar en 1980 una antología de poetas de diversas edades titulada Ganímedes 6, con poetas de diversas promociones dentro del país y algunos exiliados, como el caso de Gonzalo Millán y Oscar Hahn.

En diversos lugares del mundo, los poetas de los sesenta siguieron publicando una obra de continuidad, pero sin eludir la ruptura: es el caso de Gonzalo Millán con La ciudad (1979) en Montreal; de Waldo Rojas en Francia (El puente oculto es de 1981); de Raúl Barrientos en Estados Unidos quien publica en 1981 Ese mismo sol y en 1982 en México su obra Reino de la noche; de Jorge Etcheverry en Ottawa publicando su primer libro, una antología bilingüe que va de 1968 a 1980, titulada El evasionista/The Escape Artist; de Sergio Infante en Suecia con Sobre exilios (1979) y Retrato de época (1982); de Naín Nómez en Toronto con su libro Historias del reino vigilado/Stories of a Guarded Kingdom (1981), también una antología que va de 1964 a 1980. Habría que citar también los nombres de Erik Martínez en Canadá, de Omar Lara en Rumania, de Gustavo Mujica en París, de Hernán Valdés en Alemania, de Antonio Arévalo en Italia, de Jaime Silva en Alberta, Canadá, de Hernán Castellano Girón en California, de Edgardo Mardones en Suecia, de Roberto Bolaño en Barcelona, de Hernán Lavín Cerda en México, de Mahfud Massís en Caracas, de Bruno Montané en Barcelona, entre muchos otros.

A este largo recuento hay que agregar el desarrollo de otros poetas que se inician en Chile y publican en esos años: es el caso de José María Memet con Poemas crucificados en 1977; Jorge Montealegre con Huiros en 1979; Aristóteles España quien publica Equilibrios e incomunicaciones en 1982 en una edición artesanal, con poemas escritos en el campo de concentración de Dawson entre 1973 y 1974; Jorge Torres Ulloa con Recurso de amparo de 1975 y Palabras en desuso de 1978; Bruno Serrano con El antiguo ha sucumbido en 1979; Carlos Trujillo con Las musas desvaídas en 1977, entre muchos otros más.

Resulta indudable que en este segundo momento se ha ampliado el espectro de estéticas 
entrecruzadas entre el adentro y el afuera. Hacia 1982 la poesía que se escribe y publica en libros y revistas se hace casi incontenible en sus diversas líneas y problemáticas. Se inician los primeros diálogos en Congresos, Simposios, Encuentros Nacionales e Internacionales que se desarrollan en Chile y en todo el mundo. Las revistas Literatura chilena en el exilio de California y Araucaria de Chile de Madrid abren espacio a las variadas formas que adoptan los proyectos poéticos y esta apertura luego se verá corroborada por una variada gama de publicaciones permitidas y clandestinas en Chile. Se empieza a gestar un tercer momento, que representa el más original de la poesía del período dictatorial y un empuje fundamental para la apertura democrática.

Por otro lado, los avances y retrocesos en el campo económico, político y militar que se desarrollan al interior de las fuerzas que hegemoniza la dictadura, así como los avances y retrocesos de las fuerzas antidictatoriales al interior y exterior en este período, con sus diversas posiciones y alianzas tácticas y estratégicas, se articulan en forma dialogante, pero también en forma antitética, con los contradictorios discursos de la cultura y la literatura. Los discursos sociales hegemónicos al interior del país (orden económico, orden político, orden social, orden moral) se contradicen con los discursos contestatarios, así como los discursos críticos hegemonizan el imaginario restauratorio de los escritores más proclives al régimen (i.e. Enrique Lafourcade, José Luis Rosasco, Braulio Arenas, Carlos Iturra, además de muchos intelectuales y profesionales menos visibles), pero entran en contradicción con los discursos internos y externos críticos al régimen. Lo importante es que en los inicios de los ochenta los discursos literarios han logrado eludir la censura a partir del simulacro de la aceptación del orden, utilizando los pliegues discursivos de la parodia, la ironía, el sarcasmo, la resignificación del simbolismo del orden oficial y especialmente la deconstrucción de los significantes de todos los discursos esencializados por el sistema opresor. Vale agregar que estos intentos no fueron unívocos, que tuvieron avances y retrocesos, diversas posiciones de los actores en el campo cultural y movimientos que dependían de los pliegues, repliegues y despliegues del sistema. Todo ello se da en el contexto de una dictadura institucionalizada, reforzada por el plebiscito de 1980, erosionada por la crisis económica de comienzos de los 80 y la respuesta rotunda que fue la implementación del sistema neoliberal con la privatización de los servicios sociales, la flexibilidad laboral y la apertura de los mercados internacionales. A eso hay que agregar el despertar de la sociedad civil que se instala en los espacios públicos. Este será el escenario del momento siguiente.

\section{EL TERCER MOMENTO}

Este se desarrolla a partir de los años ochenta, tal como lo hemos anticipado en el acápite anterior y se articula con el debilitamiento de la represión dictatorial y la mayor fluidez que se produce entre la cultura del interior del país y la de los poetas que viven en el extranjero. El repliegue generalizado de la poesía que se escribía al interior empieza a desplegarse en un mayor número de publicaciones y antologías, que se entroncan con la continuidad de ciertas revistas (es el caso de La Bicicleta, que se mantiene hasta 1987 y de otras como La Castaña, La Gota Pura, Envés, Postdata), con la permanencia de los talleres literarios, el trabajo de la Unión de Escritores Jóvenes, los recitales en lugares privados y públicos, muchos de ellos amparados por la complicidad solidaria de la iglesia católica y los encuentros de poetas y críticos que se producen en Santiago, California, México, Estocolmo, Amsterdam, Madrid.

Tres fenómenos nuevos marcan este momento que muestra en forma fehaciente la riqueza y madurez que adquiere la poesía chilena como "pegamento" cultural y político, que se amplía a todos los sectores vivos de la sociedad. Estos fenómenos son:

1. Los cruces de poetas que salen de Chile a estudiar, trabajar o realizar giras por uno o más países y escritores que regresan durante la década del ochenta, ya sea en forma parcial o definitiva. Este hecho marca un incremento de la producción, la edición y la distribución de los productos literarios aumentando, por lo tanto, el intercambio a través de ediciones en Chile y otros países, las discusiones en encuentros y revistas y el entusiasmo con que se ocupan los nuevos espacios de libertad.

2. La ampliación de una escritura de poetas mujeres que se había iniciado en la década anterior de manera esporádica, pero que ahora se extiende desde la capital hacia las provincias, aunque sigue siendo una corriente fundamentalmente urbana. La profusión de voces y las diferencias de registro marcan por primera vez en la historia de la literatura chilena moderna y contemporánea una ampliación de la escritura de mujeres que se convierte en signo de tradición y permanencia. No se trata, como en momentos anteriores, de una producción deudora de las corrientes dominantes, sino de 
modulaciones específicas que culminan hacia fines del siglo XX en un catastro impresionante de escrituras heterogéneas y originales.

3. La rearticulación de los poetas del sur que, retomando lo mejor de la poesía lárica y etnocultural de los sesenta, se desarrolla desde el foco abierto de una serie de voces que utilizan la interacción entre culturas para rehacer la crónica, el testimonio, la memoria y el uso de formas coloquiales y metafóricas en una hibridez renovadora.

Estos tres rasgos de la poesía de los ochenta deben matizarse con los discursos de los poetas que siguen escribiendo con mucha energía desde los cincuenta en adelante y que también han desarrollado transformaciones en sus estéticas.

Con respecto al primer aspecto, una serie de encuentros permitirá una discusión en términos políticos y estéticos en los cuales se intenta situar la poesía de dentro y de fuera, estableciendo sus diferencias y similitudes. Si bien las revistas que publican en el extranjero, especialmente las nombradas más arriba, expresan cabalmente las diferencias y tratan de dar a conocer a las nuevas promociones, no pueden dejar de tener una cierta mirada ideológica que las hace más tradicionales que innovadoras. Literatura chilena en el exilio, creada en 1977, existe con ese nombre hasta 1981, momento en que cambia su nombre por Literatura chilena, creación y crítica, con el cual circula hasta su desaparición en 1987. Desde el primer número, la revista va a mostrar esa matriz multívoca que da el mosaico de diversas escrituras que coinciden en el tiempo, pero pertenecen a distintos grupos, promociones, estados y movimientos. En enero de 1977, junto a los tradicionales homenajes a Mistral y Neruda, que se repetirán posteriormente como una manera de exorcizar la pretensión dictatorial de apoderarse de ciertos mitos y símbolos ajenos, aparecen textos de poetas consagrados, como es el caso de Efraín Barquero, Mahfud Massís, Jaime Valdivieso, Omar Lara y Osvaldo Rodríguez. Priman los temas del hogar perdido, la soledad, la angustia $\mathrm{y}$, desde el punto de vista de la forma, un híbrido con el testimonio. A los homenajeados se sumará Vicente Huidobro y la gama de poetas canónicos se ampliará con Gonzalo Rojas, Enrique Lihn, Jorge Teillier, Humberto Díaz-Casanueva, Alfonso Alcalde, Jorge Jobet, Fernando Alegría, Antonio Campaña y otros poetas de los sesenta en proceso de escritura, como Oscar Hahn, Manuel Silva Acevedo, Waldo Rojas, Gonzalo Millán, Cecilia Vicuña, Javier Campos o Miguel Vicuña. Otros poetas que no tuvieron la posibilidad de publicar en Chile aparecen también en la revista: Eduardo Embry, Juan Armando Epple, Jorge Etcheverry, Patricia Jerez, Ana María Vergara, Manuel Jofré, Roberto Bolaño, Bruno Montané, entre otros. A partir de 1980 y en la medida que se hace más expedita la comunicación con Chile, empiezan a publicarse poemas de las promociones que emergen en el país y los poetas que inician su escritura en el exterior, dando origen a los primeros pasos de una integración que se complementa con lo que ocurre en el terreno de lo político y lo cultural en general. En forma parecida, ocurre casi lo mismo con Araucaria en Madrid: ambas revistas se transforman en la continuidad cultural de un país exiliado, lo que reduce su visión para articular de manera más integral el proceso que las vio nacer. De este modo, se privilegia extensamente el compromiso temático por sobre las rupturas estéticas, no sólo en la poesía, sino también en la novela, el teatro y los géneros anexos. Es por ello que se conoce menos a los poetas que en el interior de Chile y, en un contexto opresivo y censurador, desarrollan nuevas estrategias escriturales con una carga simbólica a veces difícil de interpretar. Hay una notoria ausencia de textos de Juan Luis Martínez, Raúl Zurita, Elicura Chihuailaf, Carlos Cociña, Rodrigo Lira, Clemente Riedemann y otros. Más notorio se hace esto en relación a las poetas mujeres, ya que se desconoce la producción de poetas como Eugenia Brito, Soledad Fariña, Paz Molina, Elvira Hernández, Teresa Calderón, Carmen Berenguer y otras que circulan profusamente en Chile. Esto obedece indudablemente a una visión artística que se repliega, como una reacción políticamente contestataria hacia la teoría del reflejo que tanto mal le hizo a las representaciones culturales de los artistas de los países socialistas.

Sería interminable mencionar aquí la amplia gama de poetas que empieza a publicar a partir de los años ochenta y más aún si se incluyen los autores ya consagrados o en vías de canonización. Bástenos con citar las nuevas producciones de Lihn, Uribe, Barquero, Rosenmann Taub, Teillier de los cincuenta; de Cecilia Vicuña, Claudio Bertoni, Oscar Hahn, Waldo Rojas, Silva Acevedo, Gonzalo Millán, Etcheverry, Nómez, Barrientos, Giordano, Floridor Pérez, Jaime Quezada, Omar Lara, Federico Schopf y tantos otros de los sesenta y los nuevos trabajos de los incipientes poetas de los setenta, incluyendo los citados por Raúl Zurita en su ensayo de 1983. A ello, habría que agregar los primeros textos de Bárbara Délano, Alexis Figueroa, Jaime Campos, Carmen Berenguer, Paz Molina, Soledad Fariña, Tomás Harris, Andrés Morales, José María Memet, Eduardo Llanos, Juan Pablo Riveros, Nicolás Miquea, Sergio Mansilla, Elvira Hernández, Mario Contreras Vega, Renato Cárdenas, Alvaro Ruiz, Teresa Calderón, Heddy Navarro, Erick Pohlhammer, Mauricio Redolés, Esteban Navarro, Alejandra Basualto y varios o varias más que sería largo detallar. Cada uno de ellos merece un análisis que aquí resultaría imposible hacer. 
Finalmente, un último escorzo sobre la crítica. Además de los autores y revistas citadas, existe una variada gama de discursos críticos que en Chile se publicó especialmente en los periódicos y revistas contestatarias "permitidas", como es el caso de La Epoca, Apsi, Hoy, Análisis y en otras aparecidas con posterioridad en Chile como El Espíritu del Valle (1985-86), Lar iniciada en Concepción y continuada en el exilio por Omar Lara o la revista Postdata con esporádicos números en diferentes momentos y un número especial dedicado a la poesía chilena entre 1960 y 1998, publicado en ese último año. También es válido citar aquí las producciones de CENECA, un centro de investigación sobre cultura, en donde se publicó una serie de cuadernos críticos sobre la literatura de la actualidad y las revistas Momentos, en que participaron los poetas Sergio Mansilla y Aristóteles España en Punta Arenas, y Paginadura de Valdivia en que con posterioridad han aparecido trabajos sobre el período. Entre los críticos que mayor preocupación han tenido para analizar esta etapa de la poesía chilena podemos mencionar a Soledad Bianchi, Tomás Harris, Iván Carrasco, Mario Rodríguez, Javier Campos Raúl Zurita, Luis Ernesto Cárcamo Huechante, Grínor Rojo, Eugenia Brito, Raquel Olea, Gonzalo Millán, Carmen Foxley, Jaime Lizama, Sergio Saldes y Yanko González, entre otros. Probablemente estoy dejando fuera una buena cantidad de críticos que habría que incorporar en un estudio más exhaustivo.

\section{CONCLUSIONES MUY PROVISORIAS}

Como reflexión general y colofón, complementando algunas líneas trazadas para nuestro proyecto por Magda Sepúlveda, habría que señalar que el Golpe Militar puede ser leído como un estadio más de la modernidad, que en su tardía expresión tuvo el propósito de acabar con un pasado que se consideró agotado, con el fin de inaugurar un nuevo tiempo. La dictadura militar se propuso una continuidad histórica con el pasado independentista del siglo XIX y, en ese contexto, los proyectos poéticos que empiezan a desarrollarse hacia fines de los setenta proponen tensiones que, por un lado, niegan este "proceso modernizador" y, por otro, se apropian de sus registros de violencia.

Una tensión tiene que ver con el concepto de historia. El Golpe es visto en algunas producciones poéticas como una caída del espíritu hegeliano dominado por la razón objetiva en la construcción de la historia. Muchos poetas van a representar el período militar como un fenómeno premoderno, como un retroceso hacia el instinto y el dominio animalesco de una naturaleza desbordada, pero no como el uso de otra razón instrumental. El quiebre rompe con la idea de humanismo que impregna la modernidad occidental con su universal abstracto que a partir de la Revolución Francesa indica que todos los seres humanos son iguales para conocer y ser libres. La teleología de la ruptura de la Ilustración que daba una finalidad a la historia y al ser humano como sujeto de esa historia habría dado paso a una visión caótica en donde desaparece el discurso de la Junta Militar que tenía su propia razón instrumental, para leerlo sólo como una desviación del proceso incólume de la modernidad. En gran medida, es este el sentido de la poesía política, la poesía militante, la poesía de protesta, tanto dentro como fuera del país.

Desde otra perspectiva, se produce una lectura que tiene como centro la nostalgia, porque la dictadura había cancelado un estadio en que el ser humano era uno con su propia naturaleza y con la naturaleza misma. Esta postura cambia el deseo de un orden social por el deseo de vivir cósmicamente, desconfía de la ilusión de orden social, porque ha comprobado que la modernidad protegía apetitos monstruosos. Desde esta desconfianza se intenta un retorno a lo Uno, que no es el mundo divino, sino el mundo anterior a los dioses, el mundo del paganismo donde el ser humano es Dios o héroe. Es una respuesta antimoderna, contraria a la modernidad del Golpe que se ve representado como un tiempo que supera el período pasado. Desde aquí se desenvuelve el poema lárico y sus continuadores en el sur del país, donde el mito del origen espacial y temporal alimenta también la llamada etnoliteratura.

Otra lectura se representa en el cambio de la relación sujeto-objeto, puesto que este vínculo se ha transformado a lo largo del proceso de la modernidad en una relación de objeto-sujeto. Hay una resistencia de ciertas voces a continuar siendo narradas desde determinados lenguaje y con determinadas estructuras que corresponden a la tradición, a una única tradición. Surge una literatura de mujeres que elaboran una escritura polémica sobre los registros ya trazados con el fin de constituir, más que "nuevos" lenguajes, "otros lenguajes". Se produce un cuerpo textual de creación verbal y crítico que interroga al canon literario androcéntrico desde sus propias prácticas verbales en el cuerpo de la letra. Se establece una "comunidad estética" y también un contracanon (Kemy Oyarzún, 1990). Pero no hay un sentido de filiación grupal. Se trata de proyectos que buscan modificar los códigos artísticos culturales vigentes más desde una perspectiva de resignificación que de reivindicación. Desde este intento fundante, la escritura de mujeres se constituye como un retorno a la vanguardia, más bien como la articulación de una neovanguardia, que pone en crisis los supuestos y las leyes 
fundacionales de la sociedad tanto en su concreción como en su simbólica. No es la única forma de la neovanguardia, pero probablemente es la más productiva. Su escritura busca desarrollar otra historia, la sepultada por la tradición patriarcal. En este proyecto se vuelve al pasado para rescatar el fantasma, lo ausente, el vacío de la representación en un gesto moderno que se proyecta al presente y al futuro para trazar nuevas huellas. Las hablantes se autocuestionan y autoevalúan, parodiando hasta el pastiche: la monstruosa, la deformada, el mimo del terror, la patipelá, la quiltra, la vida de gato, la mendiga, etc. Se diferencian de la vanguardia histórica en que no son voces proféticas, son poéticas del desecho, intervienen sobre capas devaluadas de sentido y de valor. Son textos desatendidos del mercado editorial de su momento, con una circulación restringida, una crítica indiferente y unos lectores/as mínimos/as, acotados y dispersados en un campo minado y deteriorado como era el campo cultural de los ochenta. El exilio es un "insilio" donde los sujetos se constituyen en procesos escriturales desidentificatorios, parricidas o matricidas, pero antiedípicos. Se multiplican las figuras del vacío y se producen pulsiones contra las operaciones identitarias con un movimiento de enmascaramiento textual y social, frente al poder híbrido, patibulario y vigilante, su tecnología de control y su carga de dispositivos de docilización. La indagación es sobre los repliegues del poder gatillados por el Golpe pero develados en el antes y el después, el afuera y el adentro, el aquí y el allá. Esta línea pasa a ser una de las más productivas en el nuevo escenario de los ochenta en adelante (Brito 1990, Olea 1998).

Otra forma que aparece en la representación poética es el intento de esbozar filiaciones postmodernas centradas en un sujeto fragmentado, cuyas múltiples voces ingresan al texto para desarmar al yo único, lo cual también puede considerarse otra forma de la neovanguardia. Aquí ya no está en juego la crítica sobre el mundo, sino sobre nosotros mismos, que somos ya fantasmas y nos autocelebramos como tales. Escritura que alude sólo al artificio del cual no hay escapatoria puesto que es imposible salir de la autorreferencialidad y de la metaficción. En estos textos se usa la palinodia, la retórica de la retractación, la contradicción, la incertidumbre, las dudas de la voz, las inconsistencias de la culpa, la amnesia, hasta llegar al paroxismo de no saber quién se retracta y de qué. Es el deseo de borrar al sujeto que convirtió a la razón en un monstruo. Esta línea, siendo también muy productiva, corre el riesgo de hacer de la poesía una metaficción que hace perder al sujeto no sólo su individualidad, sino también la articulación con la historia y el colectivo que la sustenta.

Todas estas posibilidades para representar los nuevos discursos de la modernidad que afloran durante el período dictatorial en nuestra poesía, y otras que apuntan meramente a una tradición que se niega a morir, se desarrollan en el período como expresiones contestatarias de una escritura que se quiere fundacional, crítica y renovadora, para contrarrestar las fuerzas de una racionalidad de la violencia que se nombra como retrógrada. En las representaciones mencionadas anteriormente, prima el gesto de enfrentar el excedente del consumo de la represión política, de la depredación económica y de la conversión del ser humano en sí mismo como objeto de consumo.

Al situarse la escritura poética en territorios fronterizos cercanos a la fractura con su propio origen, buscó y muchas veces logró generar y crear nuevos espacios de comunicación, que pudieron penetrar en los intersticios del panoptismo dictatorial y desplegar una realidad que se desmoronaba en su centro y, al mismo tiempo que se transformaba en alternativas des-bordadas que se alimentaban de sus propios márgenes.

OBRAS CITADAS

Brito, Eugenia. 1990. Campos minados. Santiago: Cuarto Propio.

Campos, Javier. 1990. "Arte alternativo y dictadura". Cuadernos Hispanoamericanos 482-483: 55-70.

—. 1998. "Lírica chilena del fin de siglo y (post)modernidad neoliberal en América Latina". Postdata 1-2: 78-91.

Cánovas, Rodrigo. 1986. Lihn, Zurita, Ictus, Radrigán: literatura chilena y experiencia autoritaria. Santiago: FLACSO.

Carrasco, Iván. 1989. "Poesía chilena de la última década (1977-1987)”. Revista Chilena de Literatura 33: 31-46.

Harris, Tomás. 1998. "Desarrollo de la poesía chilena: 1960-1990 (Una introducción)”. Postdata No 1-2: 92-115.

Macías, Sergio. 1990. "Una breve aproximación a 16 años de poesía chilena 1973-1989". Cuadernos Hispanoamericanos 482-483: 177-196.

Moulián, Tomás. 1997. Chile actual. Anatomía de un mito. Santiago: Lom Ediciones.

Olea, Raquel. 1998. Lengua víbora. Producciones de lo femenino en la escritura de mujeres chilenas. Santiago: Cuarto Propio.

Oyarzún, Kemy (ed.). 2002. Identidad y sujetos. Para una discusión latinoamericana. Santiago: Universidad de Chile.

Rodríguez, Mario y María Nieves Alonso. 1995. La ilusión de la diferencia. La poesía de Enrique Lihn y de Jaime Gil de Biedma. Santiago: Editorial La Noria. 
Yamal, Ricardo (ed.). 1988. La poesía chilena actual (1960-1984) y su crítica. Concepción: Ediciones Lar.

Zurita, Raúl. 1983. Literatura, lenguaje y sociedad: 1973-1983. Santiago: CENECA. Cuadernos de Investigación.

—. Revista Literatura Chilena en el Exilio (California, 1977-1981) y Literatura Chilena (Creación y Crítica) (1981-1987).

—. Revista Araucaria de Chile (Madrid 1978 a 1990). 